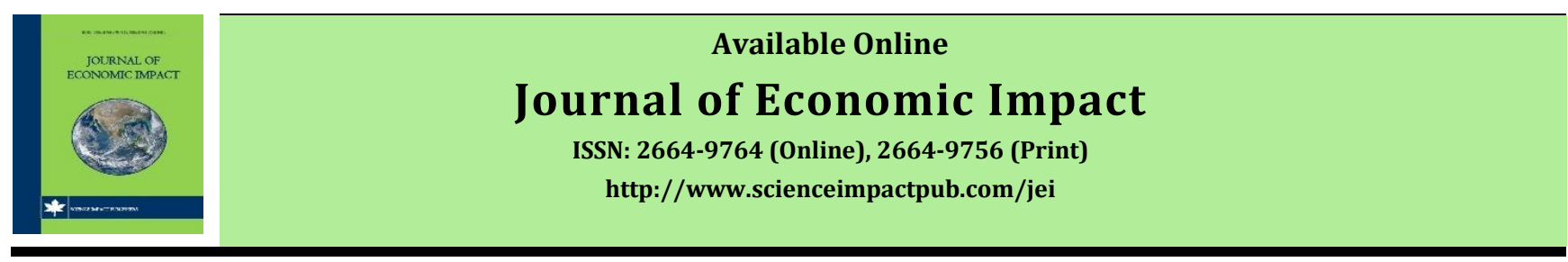

\title{
THE IMPACT OF INDIVIDUAL BEHAVIOR ON HOUSEHOLD ENERGY SAVING
}

\author{
Gulshan Maqbool a,*, Zulqarnain Haider ${ }^{b}$ \\ ${ }^{a}$ Department of Economics, University of Lahore, Sargodha Campus, Sargodha, Pakistan \\ ${ }^{b}$ School of Economics and Finance, Xi'an Jiaotong University, Xi'an, Shaanxi, P.R. China
}

\section{ARTICLE INFO}

\section{Article history}

Received: November 19, 2020

Revised: March 19, 2021

Accepted: March 21, 2021

\section{Keywords}

Energy saving

External influencing factors

Household behavior

Dwelling area
ABSTRACT

Energy-saving behaviors are defined as the daily and habitual practices of households that focus on specific reductions in energy use. The main objective of this research was to estimate the impact of the energy-saving behavior of individuals on energy demand and to estimate the impact of factors affections the adoption of energy-saving techniques. The study is based on primary data which is collected through questionnaires. The data were collected from rural and urban households in four tehsils of district Sargodha, Pakistan. The Ordinary Least Square technique was to describe the relationship between electricity consumption and different explanatory variables such as gender, age, region, family members, dwelling area, income, energy consumption awareness, external influencing factors, and household saving behavior. Job status is negative and significant, qualification variable in this study is insignificant, marital status is negatively associated with energy consumption and significant, size of a household has a significant effect on the model. The monthly income of the household head has a positive and significant effect. Energy consumption awareness is significantly negative. External influencing factors are insignificant. Saving behavior in electronic appliances is significantly negative to energy consumption. Government should put efforts to aware the public about energysaving measures through an awareness campaign using electronic media like mobile and email. Energy-saving appliances should be a sale at cheap prices. The household should have to change its habitual behavior.

\footnotetext{
*Email: gulshanmaqbool61@gmail.com https://doi.org/10.52223/jei3012105

(c) The Author(s) 2021.

This is an open access article under the CC BY license (http://creativecommons.org/licenses/by/4.0/).
}

\section{INTRODUCTION}

Pakistan is the most important country of south Asia which depended on natural gases, electricity, and wood to fulfill its energy requirements. Today energy is a very hot topic from all over the world especially in Pakistan energy is going to be shorter. Household energy consumption has become the first largest consumption sector in Pakistan. Pakistan is facing energy crises for the last two decades. Pakistan is one of the Asian countries that have natural resources but still facing energy crises. Now a day most important problem in Pakistan is the gap between the supply and demand of electricity. Pakistan is facing a 350MW (GOP, 2019) energy shortfall. Energy is ostensibly one of the most significant contributions for financial development to support modern and business exercises.
Thirty million individuals in Pakistan (about 15\% of the populace) need admittance to power, which reduces open doors for comprehensive growth. Energy interruptions and deficiencies bring about more slow financial development as well as unfavorably influence social attachment. Although the circumstance has improved with the expansion of 3,700 megawatts (MW) of age capacity somewhere in the range of 2010 and 2015, load shedding is normal and has regularly prompted common strife. Due to more readily stack the executives, the normal burden shedding, which had topped to 12 hours daily in urban and modern regions during 2013, has been diminished to 6 hours every day in urban territories and 4 hours per day in modern zones (ADB, 2010). 
Understanding the demand and supply forces and their determinants in the electricity sector is important because today our lives are directly affected by it as we have become dependent on the use of appliances run by electricity. In the light of the current electricity crisis, the topic of demand-side management has gained special significance. Despite its significance, there has been no considerable work regarding electricity demand, on household-level data, in Pakistan. Perhaps because the demand for electricity was considered as "given" or predetermined. Whatever the reason may be, the demand side of electricity is still waiting to be explored in Pakistan. We still have to develop insight into the dynamics of electricity demand in our country. Since the supply falls short of the demand and there is a continuous increase in electricity consumption, it is highly desirable to conduct a demand-side analysis regarding domestic consumers of electricity, as they constitute the largest group of electricity users. Instead of considering the supply side of electricity, the alternative option is to study the demand side approach in electricity through demand management.

Accordingly, utilization of small-scale information gives more detail and profundity when contrasted with the total level examination. Shockingly, all the investigations which have taken up this point in Pakistan have utilized total level information. Thusly there is a requirement for miniaturized scale level examination on power requests in Pakistan utilizing the small-scale information. Small scale information study is likewise significant on the grounds that it can propose something about the interest the executives' strategy. An interest in the executives' strategy could be a superior arrangement, in the short run in light of the fact that changing the flexibility of power will require a more extended time period. Also, even after increment in gracefully the interest, the board strategy will guarantee against a forced emergency with no guarantees looked at by the nation today (Hussain \& Asad, 2012). Household energy consumption is provoked by people's daily behavior. Energy-saving behavior is a daily and habitual practice of households to reduce energy consumption. Energy-saving behavior can be categorized into two categories. The first one is daily and habitual behavior, the second category of energy-saving behavior is to invest in energy-saving appliances like energy-saving bulbs, washing, dryer, etc. The third category is to build energy-saving houses (Barr et al., 2005; Black et al., 1985; Tremblay and Dillman, 1983; Akmal and Stern, 2001). Research on household energy-saving behavior has gradually taken more and more attention now a day (Barr et al., 2005; Hori et al., 2013; Jackson, 2005; Kang et al., 2012; Sweeney et al., 2013; Yue et al., 2013).
Household energy-saving behavior will be examined by using individual subjective and objective factors, external influence factors, energy-saving intension, environmental concern, social norms using as variables. He divided household behavior into two categories habitual behavior and purchasing behavior then divided it further into three categories individual characters (gender, age, occupation, degree of concern, sense of responsibilities, values), external influences factor (market, society, government, social norms, prices, policies) and energy-saving intension (habitual and purchasing energy-saving behavior). Energy-saving behavior, energy-saving intention, and influencing factors are measured on the Likert scale. Results based on Structural Equation Model. Individual subjective factors degree of concern, sense of responsibility, environmental values, energy knowledge, external influence factor education, and policies have a positive impact on energy-saving behavior while individual objective characters have an insignificant effect on energy-saving behavior (Zhang et al., 2013).

Household energy-saving behavior has been checked on socio-demographic, environmental factors, and dwelling factors. Energy-saving behavior has two types first energy-efficient appliance behavior and the second is retrofit behavior that behaviors checked by using Ordinary Least square Model (OLS), Probit Model and Nonlinear Principle Component Analyses (NLPCA), results show that environmental variable has a significant effect on energy saving behavior and energyefficient appliance investment while having an insignificant effect on energy-efficient retrofit investment, income and dwelling type variable has a significant effect on retrofit investment (Trotta, 2018). Public acceptance of household energy-saving measured in Beijing, using conjoint model showing that energysaving measure is highly acceptable while technical energy-saving measures are the least acceptance. Energy-saving measures are highly accepted among those people who have a low-income level; leaving with ring road, own houses, and have high environmental concern (Jia et al., 2018). A new method logy has been introduced for monitoring energy consumption in buildings, which applied on a real dataset of japan and proved that we can save $21 \%$ energy by applying the developed model, to change in occupant's behavior (Ashouri et al., 2018).

The problem of economic houses or retrofit investment people must face sound privacy, low construction material, control of indoor environment; late light lightings are the main problems (Zeng et al., 2018). Different indicators and proposed action to reduce the 
energy consumption significantly in the single-family house of Mexico. Researchers observed that $67 \%$ of people of Mexico spent $6 \%$ of their income on electricity and $39 \%$ of people do not follow the energy-saving techniques, 86\%people use their air conditioning equipment improperly because they do not follow the energy-efficient recommendations. If air conditioning equipment is used efficiently then $32 \%$ of energy can be saved (Macías et al., 2018).

This paper shows how people can make it easier for them to use energy more efficiently. It is not a traditional government document. It does not consider what new laws or regulations might be needed, and it does not announce a new spending program. Rather, this document focuses on the ways in which individuals respond to everyday situations and can be encouraged to waste less energy by being more energy-efficient. It does so by drawing upon a range of insights from behavioral economics and psychology, all of which are grounded in a growing body of academic evidence. Although many energy efficiency measures have been proven to be highly cost-effective (for example insulating a loft or putting in place cavity wall insulation), and therefore a 'rational' thing to do, many people are yet to introduce them. Pakistan is facing energy crises for the last decade so the question is that how to fulfill the energy demand through changes in individual behavior at the household level.

This study will explore those factors which affect the energy demand. There are two ways to reduce the gap between energy supply and demand. The first is the supply of energy and the second one is the demand for energy. The current research underhand is only related to household demand (consumption) of electricity in Pakistan. Many factors are affecting the increase in household demand of electricity which is directly related to the behavior of the individuals of the household. The current research underhand is going the check the impact of individual behavior on energy consumption which is called energy-saving behavior.

\section{METHODOLOGY}

In economics, empirical studies are mostly based on two approaches such as primary data and secondary data. In the first method, the individual behavior is observed through direct interviews and questionnaires. While in the latter approach data is collected by any institution may be public or private and can be used in different researches. In the present study, the former approach such as the questionnaire technique is used to collect data because proper data related to household energy consumption and their behavior towards consumption is unavailable from secondary sources.

\section{Sampling}

The design of questionnaires is based on simple random sampling and the feedbacks from the twotime pre-survey in Sargodha city and Shahpur of district Sargodha, Pakistan. Structured questionnaires are distributed into three sets: first, the family features and geographic area (region and dwelling area) of households; second, household energy user behavior which is divided into three subparts: energy consumption awareness, external influencing factors, and household saving behavior; third, household electricity consumption 2018-19. In the first survey, 50 questionnaires had gotten filled by respondents, and in the second survey 85 questionnaires. In total, about 800 questionnaires were distributed among households of four tehsils by post and by hand. While among these 480 questionnaires are complete and valid which are utilized for the current study.

The present study has also used a survey approach to collect primary data about energy users due to the unavailability of required household-level data based on monthly energy consumption and behavior of household energy users. In the third portion of the questionnaire, questions are asked in three subportions about household energy consumers by using the Likert scale (strongly agree, agree, neutral, disagree, and strongly disagree). The data is collected from 480 respondents from four tehsils of district Sargodha of Pakistan such as Sargodha, Bhera, Shahpur, and Bhalwal. The data sample based on tehsil distribution is shown in Table 1.

Table 1. Sample distribution.

\begin{tabular}{lccccc}
\hline Tehsil & $\begin{array}{c}\text { Issued } \\
\text { questionnaire }\end{array}$ & $\begin{array}{c}\text { Responded } \\
\text { questionnaire }\end{array}$ & $\begin{array}{c}\text { Incomplete } \\
\text { questionnaire }\end{array}$ & $\begin{array}{c}\text { Valid } \\
\text { questionnaire }\end{array}$ & $\begin{array}{c}\text { Effective } \\
\text { Rate (\%) }\end{array}$ \\
\hline Sargodha & 200 & 176 & 11 & 165 & 82.5 \\
Bhera & 200 & 147 & 16 & 131 & 65.5 \\
Shahpur & 200 & 158 & 56 & 102 & 51 \\
Bhalwal & 200 & 104 & 22 & 82 & 41 \\
Total & 800 & 585 & 105 & 480 & 60 \\
\hline
\end{tabular}




\section{Effect of Different Explanatory Variables on Energy Consumption}

A simple ordinary least square regression is used to describe the relationship between electricity consumption and different explanatory variables such as gender, age, region, family members, dwelling area, income, and z-score variables as energy consumption awareness, external influencing factors, and household saving behavior.

$$
\begin{aligned}
& \operatorname{LnEC}_{i}=\alpha_{0}+\alpha_{1} G E N_{i}+\alpha_{2} L n A G E_{i}+\alpha_{3} Q U A_{i} \\
& +\alpha_{4} J_{O B S T A T_{i}}+\alpha_{5} \text { MRSTAT }_{i} \\
& +\alpha_{6} F A M E M_{i}+\alpha_{7} D W E_{i}+\alpha_{8} R E G_{i} \\
& +\alpha_{9} L_{n I N C_{i}}+\alpha_{10} I E C_{i}+\alpha_{11} E_{-} C_{-} A_{i} \\
& +\alpha_{12} E_{-} I \_F_{i}+\alpha_{13} S_{-} B_{-} H_{-} A_{i}+\epsilon_{i}
\end{aligned}
$$

Where;

LnEC = Average monthly electricity and gas expenditures.

GEN = Gender, 1 for male and 0 for female.

AGE $=$ Age of household head.

QUA = Number of schooling years of household head.

JOBSTST = Job-status, 1 for employed and 0 otherwise.

MRSTSAT = Marital status, 1 for married and 0 otherwise.

FAMEM = Number of family members.

DWE $=$ Dwelling size.

$\mathrm{REG}=1$ for rural and 0 for urban.

LnINC $=$ Natural log of monthly income.

IEC = 1 for increasing energy cost motivate to reduce energy demand and 0 otherwise.

E_C_A = Z-score of energy consumption awareness.

E_I_F = Z-score of external influencing factors.

S_B_H_A = Z-score of saving behavior of household in electronic appliances.

$\epsilon_{i}=$ Error term

\section{Description of Variables}

Energy Consumption: In the above model, for monthly energy consumption, the average monthly electricity and gas expenditure of household consumption is taken as a dependent variable by taking the natural log.

Gender: In the gender variable male and female category is used as 1 for male and 0 for female. The gender variable is also expected to affect energy consumption positively. Age: Age affects the income of the household head as an increase in income is directly related to higher energy consumption because an experienced person can earn more than an inexperienced person and experience come with the age of an individual. The age and income of household heads are correlated. It is expected that the impact of age on energy consumption will be positive.

Qualification: Education is an important indicator describing the quality of life Literature reveals that an educated person uses more energy sources than an uneducated person. Hence literacy can raise energy consumption levels.

Job Status: It is generally accepted that employed people can increase their income level than unemployed and as the income of a person increases, he/she increases energy consumption by purchasing more appliances. The study used a job status dummy in the model where 1 means employed and 0 means unemployed.

Marital Status: Moreover, marital status often affects energy consumption levels in various ways. Married people use less energy than unmarried. Therefore this study used a marital status dummy in the estimated model where 0 is assumed for unmarried and 1 is assumed for married.

Family Size: Family size is also an independent variable which is expected to be significant as the number of family size increases electricity consumption increases.

Dwelling Size: Dwelling size includes the living area of households whether it is personally owned or rented. A dwelling area is taken in square feet. It is also expected to be a significant and positive relationship with electricity consumption.

Region: This is also a dummy variable in which two categories are included such as rural region and urban region in which rural is equal to one and urban is equal to zero. It is expected that rural households use less energy as compared to urban households.

Monthly Income: Monthly income of the household includes disposable income in which all sources of income are included such as salary, pension, or any other sources.

Increasing Energy Cost: For this variable dummy is used to ask a question that 'does increasing energy cost motivate you to change energy consumption behavior?' It is expected that it would be a significant and negative relationship with energy consumption in this study.

Energy Consumption Awareness: Energy consumption awareness includes awareness related to issues of energy, exploitation of natural resources (gas, coal, oil, etc.), and use of renewable resources (water, sunlight, and wind), etc. Past researches showed that energy consumption awareness has a negative effect on energy consumption. So, in this study, it is expected that it will negatively affect energy consumption. Energy consumption awareness is calculated by using a Likert scale such as (strongly agree, agree, neutral, disagree, and strongly disagree) 1 to 5 respectively and 1 for strongly agree and 5 for strongly disagree. These responses are then Z-scored before utilization in estimation.

External Influencing Factors: External influencing factors (social norm, public education, and occasional factors) 
includes consumption of energy of friends and family, street lights, use of energy on occasions such as marriages and birthdays, etc. Past researches showed that external influencing factors have a negative effect on energy consumption. So, in this study, it is expected that it will negatively affect energy consumption. These are also calculated by using a Likert scale such as (strongly agree, agree, neutral, disagree, and strongly disagree) 1 to 5 respectively and 1 for strongly agree and 5 for strongly disagree. These responses are then Z-scored before utilization in estimation.

Saving behavior of household in electronic appliances: Saving behavior of household in electronic appliances includes the purchase of efficient home appliances such as washing machines, air conditioners, fans, refrigerator, and bulbs, etc., another important question such as 'does you turnoff energy appliances after use?' and 'do you use unnecessary energy appliances such as dryer, dish dryer, etc.? It is expected that it will negatively affect energy consumption. Saving behavior of household in electronic appliances are also calculated by using Likert scale such as (strongly agree, agree, neutral, disagree, and strongly disagree) 1 to 5 respectively and 1 for strongly agree and 5 for strongly disagree. These responses are then Zscored before utilization in estimation.

\section{RESULTS AND DISCUSSION}

This section represents the results of the estimated model of this study which include demographic features of household, income, job status, dummy variables for such as environmental reason and increasing energy cost, Z-score for energy consumption awareness, external influencing factors, and saving behavior in case of electronic home appliances. The adjusted R-square is 0.581 which shows the goodness of fit of the model is $58 \%$. The relationship between gender and energy consumption is significant at $\mathrm{p}<0.05$ and negative. The results show that female-headed households use 0.329 percent less energy than male-headed households. Women are more cautious in case of energy consumption decisions (Carlsson-Kanyama and Lindén, 2007; Räty and Carlsson-Kanyama, 2010). Women purchase more efficient electronic appliances (Ameli and Brandt, 2015; Gaspar and Antunes, 2011). So, it is shown in many previous studies that women take decisions more intelligently as compare to men in the case of electronic appliances-related purchases and investments.

Age is significantly and positively related to energy consumption. It shows as age increases by one year the energy consumption increases by 0.005 percent. Results show that older people are automatically put behind energy conservation purposes. It shows older households consume more energy in contrast with younger households. As older people are less interested as compare to younger people in purchasing new updated technology electric home appliances and older electronic home appliances because old technology consumes more energy. That's why as age increases households seem to be less interested in energy conservation and saving. In general, older households pass more time staying at home and consume more energy than younger people in which space cooling and heating are mainly included. While younger households on the other hand stay out all day for their earnings (Poortinga et al., 2003).

Table 2. Effect of household energy consumption behavior on energy consumption.

\begin{tabular}{lcccc}
\hline Variables & $\mathrm{B}$ & Std. Error & $\mathrm{T}$ & Sig. \\
\hline (Constant) & -2.065 & 0.553 & -3.731 & 0.000 \\
Gender & -0.329 & 0.053 & -6.219 & 0.000 \\
Age & 0.005 & 0.002 & 2.733 & 0.007 \\
Qualification & 0.004 & 0.005 & 0.799 & 0.425 \\
Job status & -0.152 & 0.031 & -4.860 & 0.000 \\
Marital status & -0.192 & 0.066 & -2.890 & 0.004 \\
Family members & -0.025 & 0.009 & -2.766 & 0.006 \\
Dwelling size & 0.020 & 0.005 & 4.125 & 0.000 \\
Region & -0.006 & 0.054 & -0.114 & 0.909 \\
Monthly income & 0.681 & 0.051 & 13.422 & 0.000 \\
Increasing energy cost & -0.190 & 0.063 & -3.028 & 0.003 \\
Energy consumption awareness & -0.260 & 0.057 & -4.540 & 0.000 \\
External influencing factors & 0.032 & 0.072 & 0.445 & 0.657 \\
Saving behavior in electronic appliances & -0.152 & 0.055 & -2.785 & 0.006 \\
\hline Adj. R square & & & 0.581 & \\
No. of obs. & & & 480 & \\
\hline
\end{tabular}


The qualification variable in this study is insignificant in which the number of schooling years is taken. It shows that if one year of school will increases the energy consumption will increase by 0.004 percent. It may be significant if we take the dummies at different levels of education (e.g., primary, secondary, and university). As in many pieces of research' dummies of different levels of education are taken (Morton et al., 2018). So, the results of this variable are not according to our expectations.

Job status is negative and significant as in Table 2 which shows that unemployed households consume more energy as compare to occupants which are not according to our expectations. But it is possible because in Pakistani society there are so many families where only one family member earns bread and butter for the whole family. So, it is probably possible that households have more women kids, and older members who are not earning. The variable marital status is negatively associated with energy consumption and significant at $p<0.05$ and results are in line with expectations which shows married people have energy conservation habit in contrast with a single. On the other hand, they also purchase energy-efficient appliances and retrofits to reduce energy consumption as compared to single respondents (Trotta, 2018). Although the size of a household has a significant effect on the model it is negatively related to energy consumption which means as the size of a family will increase by one member energy consumption will decrease by 0.025 percent and these results are not according to our expectations. Though it is possible in lower-income families as poor families consume less energy by living in congested areas especially in the case of blue-collar workers whose earnings are very low to fulfill their livings.

As dwelling size will increase by one square feet energy consumption will increase by 0.20 percent. The dwelling area is also significant at $\mathrm{p}<0.05$. Large houses consume more energy as compare to small houses and flats. Besides, large houses especially with space cooling and heating systems consume more energy. In dwelling areas, all types of houses include such as rented, non-rented, flats or big houses, etc. (Santin and Fayer, 2009). The region variable is insignificant with the model, although it is negative which shows that rural people conserve more electricity as compare to urban households. The monthly income of the household head is positively significant. It shows that as income increase by one percent energy consumption will increase by 0.681 percent. As income increases households increase energy consumption expenditure by consuming more and more purchase machines for increasing quality of life. Also, they increase their living area, place space heating and cooling system, more lights, fans, refrigerators, and air conditioners, etc. (Nie and Kemp, 2014). So, for affluent lifestyle households increase their daily energy consumption.

The other dummy variable is increasing energy cost which is based on the question that does increasing energy cost motivate household to reduce energy consumption?' It is significant and negative which means as energy cost increases by one percent the energy consumption will decrease by 0.190 percent. Most previous studies had negated an increase in energy cost perspective while measuring household behavior for energy conservation but it greatly influences household behavior to conserve energy. Previous studies covered this factor only by clustering different households in case of income (Barr et al., 2005; Urban and Scasny, 2012).

Energy consumption awareness is significantly negative at $\mathrm{p}<0.05$ which shows that as one percent increase in awareness energy consumption decrease by 0.260 percent. Energy consumption awareness includes awareness related to energy issues, exploitation of natural resources (gas, coal, oil, etc.), use of renewable resources (water, sunlight, and wind), environmental upgradation, etc. The results are according to our expectations. Energy consumption awareness is collected through questionnaires by using a Likert scale such as (strongly agree, agree, neutral, disagree, and strongly disagree) 1 to 5 respectively and 1 for strongly agree and 5 for strongly disagree. These responses are then Z-scored before utilization in estimation. It is shown from the relationship of energy use awareness and energy consumption that people have awareness about renewable resources and non-renewable resources (Baul et al., 2018). Results also show that people value nature for environmental upgradation. People show some responsibility towards the environment and energy conservation according to results there is some correlation between responsible behaviors and consequences of irresponsible energy consumption habits (Poortinga et al., 2003; Steg and Vlek, 2009; Gadenne et al., 2011).

External influencing factors are insignificant to the model. These include the consumption of energy of friends and family, street lights, use of energy on occasions such as marriages and birthdays, etc. Past researches showed that external influencing factors have a negative effect on energy consumption but our results are not according to expectations. These are also calculated by using the Likert scale. The responses are then Z-scored adjusted before utilization in estimation. So, according to this study attitude of friends and family on different occasions towards energy conservation has no influence on household's behavior towards energy consumption. 
Saving behavior in electronic appliances is significantly negative to energy consumption. If a household increases the use of one more electricity-efficient home appliance the energy consumption will decrease by 0.152 percent. The saving behavior of households in electronic appliances includes the purchase of efficient home appliances such as washing machines, air conditioners, fans, refrigerators, and bulbs, etc. The results are in line with expectations. It is also calculated by using a Likert scale such as (strongly agree, agree, neutral, disagree, and strongly disagree) 1 to 5 respectively and the responses are then Z-scored before utilization in estimation. The purpose of energy conservation in the case of home appliances is influenced by choices such as refrigerators, TVs, washing machines, and other large and small appliances. These are usually purchased for a lifetime and tend to be exchanged after cessation (Platchkov et al., 2011). Although overall energy consumption for appliances including small appliances such as dishwashers, electronic devices for information and communication, increases steadily but plays a role in energy efficiency (Trotta, 2018).

\section{CONCLUSIONS}

The results of this study suggest that government or policymakers or any other energy-saving organizations need to put more attention to household profiles for less energy consumption. To encourage people to reduce their energy use and to improve their energy efficiency in the household, few policy measures are suggested. Firstly, the government needs to put efforts into aware the public about energy-saving measures through awareness complaints using electronic media like mobile, email, etc. Secondly, the most successful treatment in reducing energy consumption was found to be the deployment of smart meters coupled with the installation of real-time information displays. Thirdly, energy-saving appliances play a vital role to reduce energy consumption at the household level like as domestic appliances, electronic appliances, etc. So, the household can reduce their energy consumption by investing in energysaving appliances. Government should have to provide that entire appliance at a cheap price to the household. Fourthly, the household can save energy by habitual behavior without any monetary cost such as turning off energy appliances.

\section{REFERENCES}

ADB, 2010. Integrated energy sector recovery report and plan: friends of democratic Pakistan. Energy Sector Task Force. Retrieved from website; https://www.adb.org/sites/default/files/publicati on/27488/energy-recovery-report-plan.pdf.
Akmal, M., Stern, D., 2001. Residential energy demand in Australia: an application of dynamic OLS. The Australian National University, October.

Ameli, N., Brandt, N., 2015. Determinants of households' investment in energy efficiency and renewables: Evidence from the OECD survey on household environmental behaviour and attitudes. Environmental Research Letters, 10(4), 044015.

Ashouri, M., Haghighat, F., Fung, B.C., Lazrak, A., Yoshino, H., 2018. Development of building energy saving advisory: a data mining approach. Energy and Buildings, 172, 139-151.

Barr, S., Gilg, A.W., Ford, N., 2005. The household energy gap: examining the divide between habitual-and purchase-related conservation behaviors. Energy Policy, 33 (11), 1425-1444.

Baul, T.K., Datta, D., Alam, A., 2018. A comparative study on household level energy consumption and related emissions from renewable (biomass) and nonrenewable energy sources in Bangladesh. Energy Policy, 114, 598-608.

Black, J.S., Stem, P.C., Elworth, J.T., 1985. Personal and contextual influences on household energy adaptions. Journal of Applied Psychology, 70(1), 3-21.

Carlsson-Kanyama, A., Lindén, A.L., 2007. Energy efficiency in residences-challenges for women and men in the North. Energy Policy, 35(4), 2163-2172.

Gadenne, D., Sharma, B., Kerr, D., Smith, T., 2011. The influence of consumers' environmental beliefs and attitudes on energy saving behaviours. Energy Policy, 39(12), 7684-7694.

Gaspar, R., Antunes, D., 2011. Energy efficiency and appliance purchases in Europe: consumer profiles and choice determinants. Energy Policy, 39(11), 7335-7346.

GOP, 2019. Economic survey of Pakistan (2018-19). Economic Advisor's Wing, Finance Division, Govt. of Pakistan, Islamabad, Pakistan.

Hori, S., Kondo, K., Nogata, D., Ben, H., 2013. The determinants of household energy-saving behavior: survey and comparison in five major Asian cities. Energy Policy, 52, 354-362.

Hussain, I., Asad, M., 2012. Determinants of residential electricity expenditure in Pakistan: urban-rural comparison. Forman Journal of Economic Studies, 8, 127-141.

Jackson, T., 2005. Motivating sustainable consumption. Sustainable Development Research Network, 29(1), 30-40.

Kang, N.N., Cho, S.H., Kim, J.T., 2012. The energy-saving effects of apartment residents' awareness and behavior. Energy and Buildings, 46, 112-122. 
Macías, J.S., Tello, C.P., Ramírez, A.A., Arista, A.L., Almaguer, H.M., Escobedo, P.R., Puente, A.R., 2018. Assessment of electrical saving from energy efficiency programs in the residential sector in Mexicali, Mexico. Sustainable Cities and Society, 38, 795-805.

Morton, R.W., Murphy, K.T., McKellar, S.R., Schoenfeld, B.J., Henselmans, M., Helms, E., Aragon, A.A., Devries, M.C., Banfield, L., Krieger, J.W., Phillips, S.M., 2018. A systematic review, meta-analysis and metaregression of the effect of protein supplementation on resistance training-induced gains in muscle mass and strength in healthy adults. British journal of sports medicine, 52(6), 376-384.

Nie, H., Kemp, R., 2014. Index decomposition analysis of residential energy consumption in China: 20022010. Applied Energy, 121, 10-19.

Platchkov, L., Pollitt, M., Shaorshadze, I., 2011. The implications of recent UK energy policy for the consumer: a report for the Consumers' Association. ESRC Electricity Policy Research Group, Cambridge Electricity Policy Research Group.

Poortinga, W., Steg, L., Vlek, C., Wiersma, G., 2003. Household preferences for energy-saving measures: a conjoint analysis. Journal of Economic Psychology, 24(1), 49-64.

Räty, R., Carlsson-Kanyama, A., 2010. Energy consumption by gender in some European countries. Energy Policy, 38(1), 646-649.

Santín, M., Fayer, R., 2009. A longitudinal study of Enterocytozoon bieneusi in dairy cattle. Parasitology Research, 105(1), 141-144.
Steg, L., Vlek, C., 2009. Encouraging pro-environmental behaviour: an integrative review and research agenda. Journal of Environmental Psychology, 29(3), 309-317.

Sweeney, J.C., Kresling, J., Webb, D., Soutar, G.N., Mazzarol, T., 2013. Energy saving behaviours: Development of a practice-based model. Energy Policy, 61, 371-381.

Tremblay, K.R., Dillman, D.A., 1983. Beyond the American housing dream: Accommodation to the 1980s. University Press of America.

Trotta, G., 2018. Factor affecting energy-saving behavior and energy efficiency investments in British households. Energy Policy, 114, 529-539.

Urban, J., Ščasný, M., 2012. Exploring domestic energy-saving: the role of environmental concern and background variables. Energy Policy, 47, 69-80.

Yue, T., Long, R., Chen, H., 2013. Factor influencing energy-saving behavior of urban households in Jiangsu province. Energy Policy, 62, 665-675.

Zeng, X., Hu, Q., He, L., Liu, Z., Gao, S., Yu, Z., 2018. Occurrence, distribution and ecological risks of organophosphate esters and synthetic musks in sediments from the Hun River. Ecotoxicology and environmental safety, 160, 178-183.

Zhang, Y., Wang, Z., Zhou, G., 2013. Antecedents of employee electricity saving behavior in organizations: an empirical study based on norm activation model. Energy Policy, 62, 1120-1127.

Publisher's note: Science Impact Publishers remain neutral with regard to jurisdictional claims in published maps and institutional affiliations.

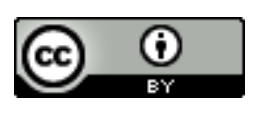

Open Access This article is licensed under a Creative Commons Attribution 4.0 International License, which permits use, sharing, adaptation, distribution and reproduction in any medium or format, as long as you give appropriate credit to the original author(s) and the source, provide a link to the Creative Commons license and indicate if changes were made. The images or other third-party material in this article are included in the article's Creative Commons license, unless indicated otherwise in a credit line to the material. If material is not included in the article's Creative Commons license and your intended use is not permitted by statutory regulation or exceeds the permitted use, you will need to obtain permission directly from the copyright holder. To view a copy of this license, visit https://creativecommons.org/licenses/by/4.0/. 